\title{
VAQUEJADA X PROTEÇÃO ANIMAL
}

\author{
Marianna Machado Moraes ${ }^{1}$
}

\section{RESUMO}

O presente artigo trata de um breve resumo sobre as teorias filosóficas sobre a Senciência e a consideração moral dos animais, correlacionando os fatos a prática esportiva brasileira denominada Vaquejada. O artigo demonstra como a vaquejada se iniciou e como o STF formulou 0 entendimento sobre essa prática baseado em documentações e em laudos relevantes que comprovavam a existência de maus-tratos e o descumprimento do disposto na Constituição. Após oito anos de discussão legislativa a proteção animal suspirou quando viu declara a inconstitucionalidade da lei estadual que regulamentava o esporte notadamente cruel, porém, se viu sem saída após manobra para Emenda Constitucional que daria fim ao esforço e resultado alcançado. O trabalho que tem como metodologia a revisão bibliográfica, traz em seu corpo os motivos pelos quais a derrota da proteção animal foi possível. Torna-se também fundamental para a percepção das tentativas de avanço legislativos e as razões para não alcançar a vitória por completo.

Palavras-Chave: animais não humanos; proteção animal; Senciência; vaquejada.

\section{ABSTRACT}

This article is a brief summary of philosophical theories about sentience and the moral consideration of animals, correlating the facts to the Brazilian sport practice called Vaquejada. The article demonstrates how the vaquejada began and how the STF formulated its understanding of this practice based on documentation and relevant reports that proved the existence of ill-treatment and non-compliance with the provisions of the Constitution. After eight years of legislative discussion, animal protection sighed when it saw the unconstitutionality of the state law that regulated the sport remarkably cruel, however, it found itself with no way out after maneuvering for a Constitutional Amendment that would put an end to the effort and result achieved. The work whose methodology is the bibliographical review, brings in its body the reasons why the defeat of animal protection was possible. It is also fundamental to the perception of legislative advance attempts and the reasons for not achieving complete victory.

Keywords: non-human animals; animal protection; Sentience; vaquejada.

\section{RESUMEN}

Este artículo trata de un breve resumen sobre las teorías filosóficas sobre la sinticiencia y la consideración moral de los animales, correlacionando los hechos con la práctica deportiva brasileña llamada Vaquejada. El artículo demuestra cómo comenzó la vaquejada y cómo la Corte Suprema formuló la comprensión de esta práctica a partir de documentación e informes relevantes que demostraron la existencia de maltrato e incumplimiento de las disposiciones de la Constitución. Después de ocho años de discusión legislativa, la protección animal suspiró cuando vio la inconstitucionalidad de la ley estatal que regula el deporte notablemente cruel, pero se encontró sin salida después de maniobrar por una enmienda constitucional que terminaría con el esfuerzo y el resultado logrado. El trabajo que tiene como metodología la revisión bibliográfica, trae en su cuerpo las razones por las que la derrota de la protección animal fue posible. También se vuelve fundamental para la percepción de los intentos de progreso legislativo y las razones para no lograr la victoria por completo.

Palabras clave: animales no humanos; protección de los animales; Senticiencia; vaquejada.

1 Pós-Graduada em Direito Público, Mestre em

Ciências Jurídico Políticas e Ativista Animal. 


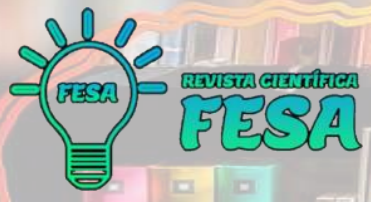

\section{INTRODUÇÃO}

Amparada nas teorias de grandes filósofos como Peter Singer, Hans Jonas, Rychard Ryder e Tom Regan o status dos animais vai sendo defendido e amparado ao longo dos tempos, porém, ainda conta com um longo caminho a percorrer para que a prática e a teoria do bem viver entre animais, sejam eles animais humanos ou não humanos, seja equilibrada.

No Brasil, o Direito Animal se orienta no sentido de dispersar os conceitos produzidos pela filosofia animalista: a consciência e a Senciência animal, o valor inerente de cada animal, a dignidade animal. ${ }^{2}$ A partir desses achados da filosofia (e da ciência), o Direito Animal edifica sua própria normatização e cientificidade, emancipando-se, assim, do Direito Ambiental. Os animais, para o Direito Animal, interessam por si próprios, independentemente da sua função ecológica ou ambiental.

Não obstante, por que, apesar dessa densidade normativa, gerada pelo próprio texto constitucional, o Direito Animal brasileiro ainda engatinha como um campo jurídico a influenciar decisões e políticas? A resposta, no entendimento de Ataíde Júnior ${ }^{3}$ continua a mesma: o direito positivo não reconhece, ainda, que os animais são titulares de direitos fundamentais, direitos fundamentais de $4^{\mathrm{a}}$ ou

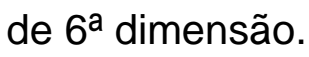

O julgamento do Supremo Tribunal Federal sobre a proibição da vaquejada no Brasil, atividade intrinsecamente cruel com os bovinos e equinos envolvidos, teve como decisão do Ministro Luís Roberto Barroso, que, embora reconheça a "inevitabilidade histórica" do Direito Animal (e do vegetarianismo), a afirmação de que apesar de ainda não ser reconhecido aos animais a titularidade de direitos jurídicos, estes são seres sencientes e têm, ao menos, o direito de não serem submetidos à crueldade e maus tratos. ${ }^{4}$ Por essa razão, o presente artigo visa

2 FERREIRA, A.C.B.S.G. Direito Animal em Xeque. Curitiba: Juruá Editora, 2018. p. 48.

3 ATAIDE JUNIOR, V.P. Introdução ao Direito Animal brasileiro. Revista Brasileira de Direito Animal. Salvador, v. 13, n. 3, pp. 48-76, set./dez. 2018. p. 51.

4 VAQUEJADA MANIFESTAÇÃO CULTURAL ANIMAIS CRUELDADE MANIFESTA PRESERVAÇÃO DA FAUNA E DA FLORA INCONSTITUCIONALIDADE. A obrigação de o Estado garantir a todos o pleno exercício de direitos culturais, incentivando a valorização e a difusão das manifestações, não prescinde da observância do disposto no inc. VII do artigo 225 da Carta Federal, o qual veda prática que acabe por submeter os animais à crueldade. Discrepa da norma constitucional a denominada vaquejada (STF, Pleno, ADI 4983, Rel. 


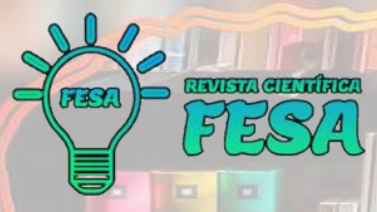

desmembrar os fatos ocorridos no cerne deste julgamento e as razões que levaram a Vaquejada a ser considerada patrimônio cultural do país, mesmo com todas as razões para ser abolida completamente.

\section{BREVE HISTÓRICO DESSA PRÁTICA}

A vaquejada surgiu no século XIX, na região do Nordeste brasileiro. Naquele tempo, as fazendas de pecuária não possuíam cercas para separar o gado. Assim, não era incomum que boiadas de diferentes fazendeiros se misturassem pelos pastos. Quando os vaqueiros precisavam separar os seus bois, alguns animais apresentavam dificuldade de locomoção e era preciso puxá-los pelos seus rabos e derrubá-los ao chão. Com o tempo, os vaqueiros foram criando habilidade na atividade e a prática de derrubar o boi se transformou em um esporte. ${ }^{5}$

Enquanto esporte, a vaquejada é praticada por pares de vaqueiros, cada um montado em seu respectivo boi, cujo objetivo é encurralar o boi do vaqueiro adversário e derrubá-lo puxando-o pelo rabo. A dupla vencedora é a que consegue acumular maior número de pontos. Para conseguir conquistar todos os pontos, é necessário deixar o animal com as quatro patas apontadas para cima. Contudo, é comprovado que o boi ao ser derrubado pelo rabo pode sofrer graves ferimentos e lesões, principalmente na região da coluna vertebral. ${ }^{6}$

Geuza Leitão, em breves linhas, define a realidade das vaquejadas destacando os requintes de crueldades que são aplaudidos pelo público:

O espetáculo é realmente chocante para uns, delirante e enlouquecedor para outros [...]. O espaço onde o novilhote ou garrote vai correr é diminuto e dois cavaleiros adestrados acompanham a vítima, empareIhados cada um tentando segurar a cauda do animal que é jogado ao chão sucedendo as mais das vezes, que leva na mão a cauda do animal caído e este muitas vezes tem as patas quebradas desastrosas.

Min. MARCO AURÉLIO, j. em 06.10.2016, publicado em 27.04.2017). BRASIL. Supremo Tribunal Federal. Ação Direta de Inconstitucionalidade - ADIN no 4.963. [Em linha]. Rel. Ministro Marco Aurélio. Julg. 15.12.2016. Publ. 31.01.2017. [Consult. em 30 Dez. 2020]. Disponível em: <http://portal.stf.jus.br/processos/detalhe. asp?incidente=4425243>.

5 BALTAZAR, S.M. Justiça Ecológica. Curitiba: Juruá Editora, 2019. p. 63.

6 NEXO. O que é vaquejada. E porque ela foi proibida pelo Supremo. [Em linha]. 2016. [Consult. em 21 Dez. 2020]. Disponível em: <https://www.nexojornal.com.br/expresso/2016/10/16/Oque-\%C3\%A9-a-vaquejada.-E-por-que-ela-foi-proibida-pelo-Supremo>. 
Enquanto isso a multidão delira numa expansão esfuziante e histérica de gritos e apupos. Tanto o cavalo como a rês mutilada são sacrificados a tiro ali mesmo diante a multidão desassisada. ${ }^{7}$

Sabe-se que o evento das vaquejadas movimenta valor monetário de grande monta. ${ }^{8}$ Somente no ano de 2013, a atividade moveu mais de 50 milhões de reais, e, em 2017, ficou constatado que a atividade gerou mais de 700 mil empregos, a partir da cadeia produtiva mantida pelo esporte. ${ }^{9}$

Embora supostamente revestida de uma natureza cultural e esportiva, a realidade é que a vaquejada tem demonstrado que pode ocasionar práticas cruéis, acarretando a disseminação de diversas formas de maus-tratos contra os bovinos, especialmente os maus tratos físicos.

\section{O INÍCIO DO FIM}

A Lei no 15.299/2013 é uma lei estadual, aprovada no dia 8 de janeiro de 2013, com o objetivo de regulamentar a prática da vaquejada no Estado entendendo-a como uma atividade esportiva e cultural de grande representatividade no Estado.

Foi impetrada pela Procuradoria Geral da República Ação Direta de Inconstitucionalidade - ADIN de $\mathrm{n}^{\circ}$ 4983, contra este diploma legal, com pedido liminar para a suspensão imediata da eficácia da Lei Estadual no 15.299/2013, tendo como objetivo principal o pedido para que fosse declarada a inconstitucionalidade da lei em razão dos sofrimentos causados aos animais tanto antes do "espetáculo" como durante e após ele.

A ação foi pedindo a inconstitucionalidade da integralidade do texto da lei do Estado do Ceará (a já citada Lei no 15.299/2013) por afronta ao direito fundamental ao meio ambiente, reconhecendo a existência, no entanto, de conflito entre a preservação do meio ambiente e a proteção conferida às manifestações culturais.

Defendeu o parquet a prevalência, no caso, do direito ao meio ambiente, por considerar que a prática da vaquejada - mesmo que considerada como

LEITÃO, G. $\boldsymbol{A}$ voz dos sem voz: Direito dos animais. Fortaleza: INESP, 2002, p. 17

8 SIQUEIRA FILHO, V.; LEITE, R.A.; LIMA, V.B. A prática da vaquejada em xeque: considerações sobre a Ação Direta de Inconstitucionalidade n. 4.983. Revista Brasileira de Direito Animal, v.10, n.20, pp. 59-80, 2015, p. 68.

9 BALTAZAR, S.M. Justiça Ecológica. Curitiba: Juruá Editora, 2019, p. 64. 

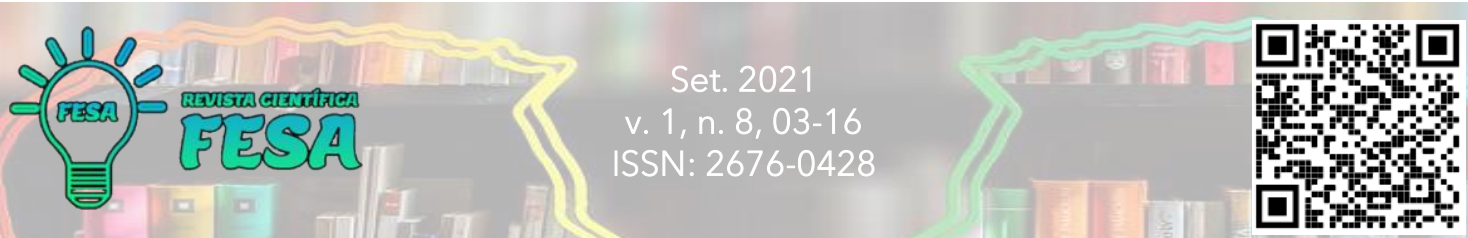

manifestação cultural ou esporte e que movimente milhões de reais - causa, comprovadamente, danos irreversíveis aos animais, expondo-os a maus tratos. Para comprovar as alegações, citou-se laudo técnico produzido, bem como estudo técnico conduzido pela Universidade Federal de Campina Grande/PB.

Ademais, ressaltou-se que a jurisprudência da Corte Maior já havia consolidado o entendimento de que o conflito entre meio ambiente e manifestações culturais, quando exista prática que trate os animais de forma inadequada, precisa ser solucionado em prol do meio ambiente, como em casos concretos, a exemplo da "briga de galo" e da "farra do boi". Por esta razão, em meio a outras causas, a prática da vaquejada também foi declarada inconstitucional, considerando-se o respeito a teoria dos precedentes consolidados sob pena inclusive de se desconstituir a nova ordem processual civil.

A ADIN n 4983/CE foi distribuída e teve como Relator o Ministro Marco Aurélio Mello, que em 27.07.2013, indeferiu a medida liminar, por entender que pela natureza da discussão deveria ser aguardada a decisão definitiva de mérito. Oficiou-se o Governador do Ceará, a Assembleia Legislativa do Ceará, bem como a Advocacia Geral da União para manifestação e o Procurador Geral da República para parecer.

Em 26.08.2013 o Governador do Ceará foi chamado a prestar informações, ocasião em que defendeu a constitucionalidade da Lei impugnada, sob o fundamento de que a vaquejada integra a cultura daquele estado, sendo reconhecida já há muitas décadas como uma prática desportiva, bem como a citada Lei Estadual buscou regulamentar a atividade, para assegurar a proteção da integridade dos animais participantes.

A Assembleia Legislativa do Ceará não prestou informações. Em 06.09.2013 a AGU apresentou manifestação, alegando, em síntese, preliminarmente inépcia da petição inicial por, supostamente, o autor não ter se desincumbido do ônus da impugnação específica, por não apontar os artigos que a lei impugnada estaria violando a CRFB/1988. Entretanto, no mérito, pugnou pela procedência da ação, pela declaração de inconstitucionalidade da Lei Estadual, pelos fundamentos elencados pelo autor, notadamente a jurisprudência do STF que reconhece que a proteção ao meio ambiente prevalece sobre práticas culturais e desportivas. Referidas informações são as mais importantes para que as questões referentes à crueldade sejam discutidas. 
O Relator Ministro Marco Aurélio sublinhou que naquela Ação, foi ressaltado pelo Relator que o STF, em se tratando de temas envolvendo crueldade contra os animais, tem reiterado, em diversos julgamentos, que esta prática se mostra frontalmente incompatível com o que dispõe o artigo 225 , § 1르. inciso VII, da CRFB/1988. ${ }^{10}$

Assim, permanece o raciocínio intelectual, que dispõe que existindo prova de maus tratos aos animais, em eventos de natureza cultural ou desportiva, a interpretação sobre a primazia de um sadio direito ao meio se mostra a conclusão mais correta. ${ }^{11}$

O Relator também afirma que existem estudos que demonstram que os cavalos utilizados na atividade também sofrem danos muitas vezes irreparáveis e de grande magnitude: tendinite, tenossinovite, exostose, miopatias focal e por esforço, fraturas e osteoartrite társica.

No caso, foi destacado pelo Relator que o autor agrupou laudos técnicos que esclarecem sobre os danos suportados pelos animais devido à intensa tração no rabo, aliado às quedas, patas fraturadas, vasos sanguíneos distendidos, traumas e ligamentos rompidos. Em casos mais graves pode ocorrer até mesmo o arrancamento do rabo, o que compromete a medula espinhal e causa, além de intensas dores físicas, estresse ao animal. Em seu voto, o ministro Marco Aurélio esclarece que as argumentações defendendo a constitucionalidade da norma, sob a alegação de que se a prática for disciplinada é possível preservar a saúde dos animais, não subsiste posto que em razão da forma como é desenvolvida, indiscutivelmente a crueldade para com os bovinos é inerente à vaquejada. $O$ ato de perseguir animal em movimento e em alta velocidade, puxá-lo pelo rabo até que este caia, configura maus-tratos. Não existe possibilidade de o boi, quando submetido a esses tratamentos, não sofrer com estresse ou com a dor física.

10 BRASIL. Supremo Tribunal Federal. Ação Direta de Inconstitucionalidade - ADIN no 4.963. [Em linha]. Rel. Ministro Marco Aurélio. Julg. 15.12.2016. Publ. 31.01.2017. [Consult. em 30 Dez. 2020]. Disponível em: <http://portal.stf.jus.br/processos/detalhe.asp?incidente $=4425243>$.

11 FERREIRA, A.C.B.S.G. Direito Animal em Xeque. Curitiba: Juruá Editora, 2018, p. 75. 


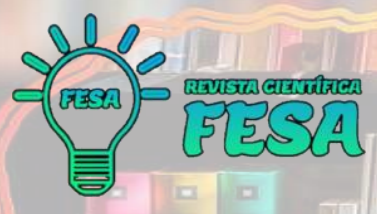

Por derradeiro, ao fim de sua longa e cuidadosa argumentação, o Ministro relator votou pela Inconstitucionalidade da lei, tendo em vista que o sentido da palavra "crueldade" que consta ao fim do inciso VII do $\S 1^{\circ}$ do artigo 225 da CRFB/1988, atinge, indiscutivelmente, a tortura, crueldade e os maus-tratos contra os bovinos no decorrer da prática impugnada, revelando-se intolerável referida conduta humana. Finalizou o seu voto justificando que para compor os interesses fundamentais em discussão, a proteção ao meio ambiente e, consequentemente, ao animal que padece de maus-tratos, deveria avultar.

Assim, o Ministro relator interpretou o inciso VII, do $\S 1^{\circ}$, do artigo 225 , da Magna Carta, em que a expressão "crueldade" alcançaria a tortura e maus-tratos aos quais os bois são submetidos durante as vaquejadas e que essa conduta humana não poderia ser consentida pela lei atacada.

Nesse contexto, a proteção ao meio ambiente deveria se sobressair em relação à manifestação cultural. De modo que a Lei oㅜ 15.299/2013, do Ceará deveria ser considerada inconstitucional. Assim, esse foi o posicionamento adotado pela maioria da Corte.

Complementarmente, adverte o Ministro Barroso que a vaquejada, no entendimento da própria Associação Brasileira de Vaquejada é vista como uma "atividade recreativa competitiva, com características de esporte"12 que se transformou a partir da década de 1990, em um grande evento, capaz de atrair multidões que tinham interesse não somente na competição, mas também nas atrações que o evento reunia, especialmente exibição de shows musicais. Afirma que não é possível negar seu caráter de manifestação cultural tradicional, mas que se trata de evento onde a crueldade contra os animais ocorre e nenhuma manifestação poderia evitar a prática a que esses animais são submetidos, e a vedação de crueldade contra os animais deve ser considerada norma autônoma, não podendo a proteção aos animais se dar com vista a preservação do meio ambiente, pois os animais não humanos não podem ser reduzidos simplesmente a elementos do meio ambiente. ${ }^{13}$

12 BRASIL. Supremo Tribunal Federal. Ação Direta de Inconstitucionalidade - ADIN no 4.963 . [Em linha]. Rel. Ministro Marco Aurélio. Julg. 15.12.2016. Publ. 31.01.2017. [Consult. em 30 Dez. 2020]. Disponível em: <http://portal.stf.jus.br/processos/detalhe.asp?incidente $=4425243>$.

13 BRASIL. Supremo Tribunal Federal. Ação Direta de Inconstitucionalidade - ADIN no 4.963. [Em linha]. Rel. Ministro Marco Aurélio. Julg. 15.12.2016. Publ. 31.01.2017. [Consult. em 30 

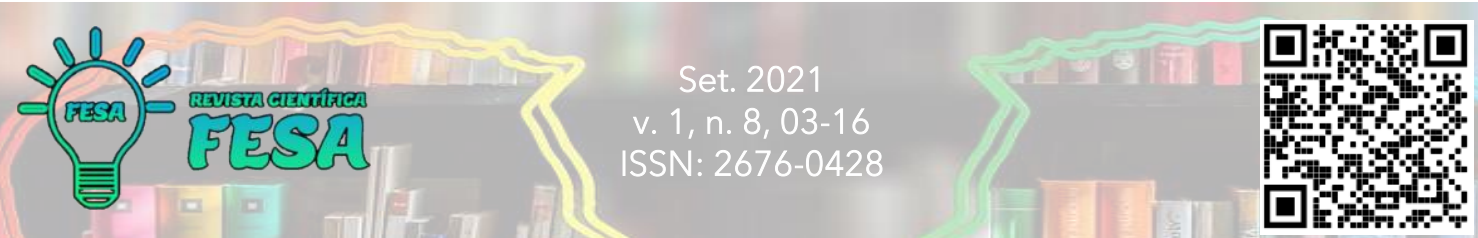

Para o Ministro Luiz Barroso, ${ }^{14}$ devem os animais serem protegidos contra a crueldade não somente como uma função da tutela destinada a outros bens jurídicos, mas sim como um valor autônomo. ${ }^{15}$

Sendo assim, a prática da vaquejada foi considerada cruel e deixaria de existir, porém foi proposta Emenda Constitucional de n 96/2017 posteriormente ao julgamento da ADIN no 4983. A EC, que leva o apelido de "Emenda da Vaquejada" vai contra o posicionamento adotado pelo STF na ADIN julgada, no entanto, trata-se de conflito apenas aparente de normas, pois, não se pode considerar como manifestação cultural uma prática que implique em sofrimento a um ser vivo.

Os conceitos de cultura e características mostram a diversidade conceitual, mas, no seu conjunto, possibilitam entender o que é cultura. Ousa-se afirmar que os conceitos de cultura e suas características são tantas quantas são as culturas. Dos conceitos e características referidos extraímos o seguinte: a) há diversas culturas; b) não existe hierarquia quando se trata de cultura, tendo em vista que todas são culturas; c) a cultura é uma construção do homem; d) os seres humanos não são imunes às influências de culturas; e) a cultura varia no tempo e no espaço; f) a cultura tem uma variedade de saberes, artes, religiões, moral, leis, ética, direito, tipos de família, usos e costumes; g) é possível a mudança de uma cultura, assim como criar outra. ${ }^{16}$

Na linha dessa noção de cultura, na ADIN no 4983/CE, em que foi apreciada a constitucionalidade de lei do Estado do Ceará sobre a vaquejada, o Ministro Edson Fachin, citando as pontuações acima realizadas a partir de conceitos de cultura, asseverou em seu voto que em uma sociedade aberta e plural como é o caso da sociedade brasileira, a noção de cultura é construída e se encontra estreitamente relacionada a uma noção mais ampla do que a que se tem de meio ambiente. ${ }^{17}$

Se o entendimento for de que não é crueldade o uso de animais em práticas desportivas, se estas forem apenas consideradas manifestações culturais, 0

Dez. 2020]. Disponível em: <http://portal.stf.jus.br/processos/detalhe.asp?incidente $=4425243>$.

14 Ibidem

15 Ibidem.

16 WESCHENFELDER, P.N. Constituição e Cultura Ambiental. Curitiba: Juruá Editora, 2019, p. 129.

17 STF - Pleno - ADIN no 4983/CE. Decisão: 6-10-2016. 


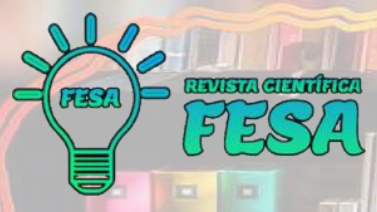

inciso VII, do parágrafo primeiro do artigo 225 da Constituição Federal da República Federativa do Brasil que assegura a incumbência do Poder Público na proteção da fauna e da flora, vedando práticas que ameacem sua função ecológica, levem à extinção de espécies ou instituam a crueldade contra os animais, torna-se não mais útil.

\section{VISÃO DA DOUTRINA}

Como bem demonstra Ferreira, ${ }^{18}$ preservar 0 meio ambiente e, especialmente, os animais não humanos, em razão da sua função ecológica são princípios constitucionais e, portanto, fundamentos do Estado de Direito. Deste modo, há novas linhas de conduta que são impressas e captadas paulatinamente pela sociedade, ensejando uma crescente mudança de consciência tendo em vista as crises ambientais e os maus-tratos aos animais.

Ademais, persiste o entendimento de que o Poder Público deve proteger a fauna e flora e consequentemente, interditar as práticas que coloquem em risco sua função ecológica.

Ao discorrer sobre o tema, Ingo Wolfgang Sarlet entende que o direito ao meio ambiente ecologicamente equilibrado pode ser considerado como sendo um dos direitos fundamentais de terceira dimensão, pois é considerado como sendo um direito difuso e que objetiva a existência digna do ser humano, tanto na sua dimensão individual, como na social. ${ }^{19}$ Portanto, entende-se perfeitamente que o meio ambiente ecologicamente equilibrado está diretamente interligado à dignidade da pessoa humana.

Portanto, a crueldade em face aos animais pode ser considerada como maus-tratos e a doutrina entende que há afronta ao princípio do meio ambiente ecologicamente equilibrado.

Também, a proteção aos direitos dos animais pode ser observada nos três princípios trazidos pela Convenção da Biodiversidade (CDB), quais sejam:

18 FERREIRA, A.C.B.S.G. A Proteção aos Animais e o Direito: o status jurídico dos animais como sujeitos de direito. Curitiba: Juruá Editora, 2014. p. 51.

19 SARLET, I.W. A Eficácia dos Direitos Fundamentais: uma teoria geral dos direitos fundamentais na perspectiva constitucional. 11. ed. rev. e atual. Porto Alegre: Livraria do Advogado, 2012. p. 236. 


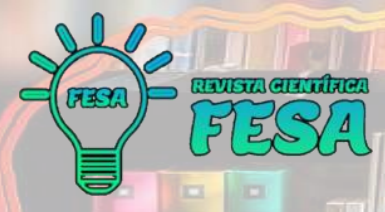

a) considerar o valor intrínseco da biodiversidade, ou seja, além de encarar a biodiversidade como recurso explorável, valoriza suas propriedades fundamentais, como a manutenção do equilíbrio ecológico e da diversidade genética, além dos aspectos sociais, científicos, educacionais, recreacionais e estéticos;

b) reafirmar o direito soberano dos Estados sobre seus próprios recursos biológicos e genéticos;

c) reafirmar a responsabilidade dos Estados pela conservação de sua biodiversidade e pela utilização sustentável de seus recursos biológicos. Merece destaque a inauguração do paradigma da soberania nacional sobre a biodiversidade, impondo a responsabilidade de regulamentação de seu acesso aos próprios países detentores.

Outro ponto importante da Convenção é o reconhecimento da importância dos conhecimentos tradicionais para a manutenção da biodiversidade. ${ }^{20}$

Conforme referido, o protecionismo aos animais fortaleceu-se com o teor da Carta de 1988, a qual elevou os bens ambientais à condição de bem público, passando a receber uma especial atenção por parte do legislador por meio do artigo 225, $\S 1^{\circ}$, inciso VII, o qual, abrigando toda e qualquer classificação de animais, obrigou o Poder Público a dedicar proteção à fauna.

A vedação constitucional da crueldade alicerça uma inovadora mentalidade do legislador, atrelada à inserção no sistema normativo nacional de parâmetros novos, a permear a relação jurídica entre homens e animais não humanos.

Deve-se diferenciar a proteção da fauna e da flora, da expressa vedação de práticas que submetam os animais a crueldade, em que se concebe uma identificação do animal não humano com interesses próprios e autônomos se comparados com os dos humanos.

Assim, o legislador elegeu parâmetros de grande importância que não podem ser ignorados, esquecidos ou desprezados pelo aplicador do Direito e, dentre estes, encontra-se a normatividade protetiva, que renega os maus-tratos.

20 AZEVEDO, C.M.A. et al. A convenção sobre a diversidade biológica no Brasil: considerações sobre sua implementação no que tange ao acesso ao patrimônio genético, conhecimentos tradicionais associados e repartição de benefícios. Revista de Direito Ambiental, a. 10, n. 37 , p 113-143, jan./mar. 2005. 


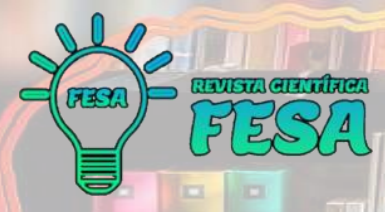

Set. 2021

v. 1, n. 8, 03-16

ISSN: 2676-0428

Saliente-se que esta prescrição está contida no Título VIII da CRFB/1988, que versa sobre a Ordem Social e caberá ao Estado e à coletividade proteger os animais contra a crueldade, como fruto das garantias de bem-estar e da justiça sociais.

No direito brasileiro, portanto, o ponto de partida para a defesa dos

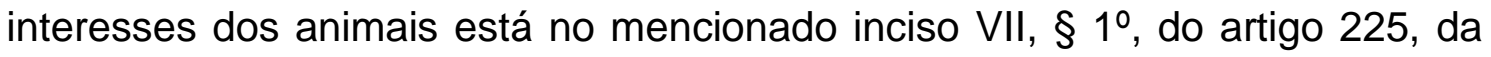
CRFB/1988, que proíbe, "na forma da lei", as práticas cujo efeito material seja a submissão dos animais à crueldade.

De fato, como acertadamente expõe Ferreira, ${ }^{21}$ a CRFB/1988, pela primeira vez na história, elevou a proibição da crueldade contra os animais ao status de preceito constitucional e, em respeito ao princípio da efetividade, não se admite qualquer exploração institucionalizada dos animais sem que essa norma constitucional seja violada.

Faz-se necessário reconhecer que os animais são seres sensíveis, cabendo a todos respeitar a vida, oferecendo os meios para que a norma constitucional expressa no artigo $225, \S 1^{\circ}$, inciso VII se efetive, vedando práticas que se mostrem ofensivas e degradadoras da integridade física destes, e banindo a crueldade e todo modo de exploração.

Frente a este aparente conflito de normas entende-se que a norma que institucionaliza os maus tratos aos animais não pode prevalecer, a necessidade da reeducação do homem para que ele não seja um sujeito a parte da natureza e sim parte dela, em que se coloca na pele do outro ser que sente a dor e o sofrimento do animal, e que não entende que a prática esportiva como entretenimento pode se sobrepor a dor de outro animal senciente.

O impacto da narrativa do que acontece na vaquejada vai de encontro a teoria do bem viver, e a reeducação da sociedade no campo ético-político urge. Cotejando-se os direitos de um ser humano com os direitos dos animais não humanos como indivíduo ou espécie, observa-se que ambos têm direito de ter seus direitos fundamentais defendidos, a exemplo do direito à vida, ao livre desenvolvimento de sua espécie, da integridade de seu organismo, além do direito ao não sofrimento. Em uma ótica ética e científica, não é difícil justificar a

21 FERREIRA, A.C.B.S.G. A Proteção aos Animais e o Direito: o status jurídico dos animais como sujeitos de direito. Op. cit., p. 52.

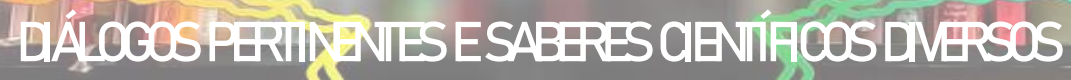


personalidade do animal. Segundo Peter Singer:

[...] a compreensão do princípio da igualdade aqui aplicado é tão simples que não requer mais que a compreensão do princípio da igualdade de interesses. Se quisermos comparar o valor de uma vida com outra, teremos que começar por discutir o valor da vida em geral. ${ }^{22}$

Nesse contexto, convém destacar que a emergência da temática dos direitos humanos a partir dos anos de 1970 trouxe o aprofundamento da sua teoria, a ampliação da sua positividade e a irradiação da jus fundamentalidade para outros campos do direito e para outras áreas do conhecimento jurídico. Entre estes últimos surge o direito dos animais, como objeto de regramento e de especulação jurídica e ética.

Fica claro, então, que a ética aqui defendida não visa abrandar o sofrimento imposto aos animais, mas, partindo de uma conduta humana coerente, faz-se necessário que as vidas de tais indivíduos sejam consideradas relevantes, bem como seus interesses primordiais. Uma ética que tenha por base a conduta humana em todos os aspectos da sociedade deve prezar pela moralidade das ações humanas tendo em vista o 'outro' como um indivíduo também capaz de afetar-se por seus atos.

Contudo, a EC № 96 alterou o artigo № 225 da CRFB/88 introduzindo o $§ 7^{\circ}$ que diz que não considera cruéis as práticas desportivas que utilizem animais, sendo assim, o Estado do Ceará conseguiu editar nova lei para regular a prática da vaquejada, a Lei ํㅜ 16.321/2017 mascara em seu corpo o artigo 4ํ que diz que a integridade física dos participantes, inclusive dos animais, deve ser observada.

A edição da Lei foi exatamente no mesmo ano da EC alterar o texto legal, deixando limpo o caminho para que a prática fosse mantida.

\section{CONSIDERAÇÕES FINAIS}

Nesse contexto, vimos que o entendimento da instância máxima superior do país, corroborada por laudos e documentos comprovando a crueldade de um espetáculo que se iniciou em outro século, não foram suficientes para abolir o esporte. A única questão que fica evidente é o lucro de mais de 50 milhões de

22 SINGER, P. Ética Prática. São Paulo: Martins Fontes, 2006, p. 59. 


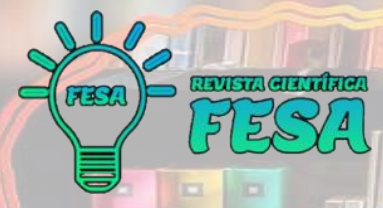

Set. 2021

v. 1, n. 8, 03-16

ISSN: 2676-0428

reais por ano que são movimentados pela vaquejada.

A consideração moral dos animais ainda é uma questão pendente no país e pode ser atracada dessa forma apenas por questões financeiras. O egocentrismo dos legisladores não permite ver além dos números. Se elevar a condição moral, como a Senciência vem provando ao longo do tempo, textos legais como esse não existiriam. Sendo assim, depois de 8 anos de luta de ativistas e políticos simpáticos a causa, e de uma breve vitória na causa animal, as manobras legislativas ainda são capazes de prevalecer.

O que se vê é que apesar dos avanços em todo o mundo no que concerne aos direitos dos animais não humanos, ainda há necessidade de mudança da mentalidade da sociedade, de reeducação cultural para que isso possa efetivamente ser vislumbrado.

O rodeio é uma prática cultural que também utiliza animais de grande porte e movimenta bilhões de reais por ano, valor muito superior ao da vaquejada, e portanto permanecem intocáveis. Com a reeducação social e demonstrações como essa, mesmo que no final tenha tido desfecho diferente do esperado, as futuras gerações, com toda essa informação perceba que esse tipo de evento cultural que se iniciou no país em outro século, só é mantido em razão de incentivo de pecuaristas que veem esses eventos como oportunidade de projeção de suas marcas, venda de produtos e outros meios de ganhar dinheiro. Que apesar dos empregos e valores arrecadados, há o lado humanitário que deveria prevalecer a tudo isso, se os animais fossem considerados moralmente pelos humanos.

\section{REFERÊNCIAS BIBLIOGRÁFICAS}

ATAIDE JUNIOR, V.P. Introdução ao Direito Animal brasileiro. Revista Brasileira de Direito Animal. Salvador, v. 13, n. 3, pp. 48-76, set./dez. 2018.

AZEVEDO, C.M.A. et al. A convenção sobre a diversidade biológica no Brasil: considerações sobre sua implementação no que tange ao acesso ao patrimônio genético, conhecimentos tradicionais associados e repartição de benefícios. Revista de Direito Ambiental, a. 10, n. 37, jan./mar. 2005.

BALTAZAR, S.M. Justiça Ecológica. Curitiba: Juruá Editora, 2019. 
BRASIL. Supremo Tribunal Federal. Ação Direta de Inconstitucionalidade ADIN no 4.963. [Em linha]. Rel. Ministro Marco Aurélio. Julg. 15.12.2016. Publ. 31.01.2017. [Consult. em 30 Dez. 2020]. Disponível em: <http://portal.stf.jus.br/processos/detalhe.asp?incidente $=4425243>$.

FERREIRA, A.C.B.S.G. A Proteção aos Animais e o Direito: o status jurídico dos animais como sujeitos de direito. Curitiba: Juruá Editora, 2014.

FERREIRA, A.C.B.S.G. Direito Animal em Xeque. Curitiba: Juruá Editora, 2018.

LEITÃO, G. A voz dos sem voz: Direito dos animais. Fortaleza: INESP, 2002.

NEXO. O que é vaquejada. E porque ela foi proibida pelo Supremo. [Em linha]. 2016. [Consult. em 21 Dez. 2020]. Disponível em: <https://www.nexojornal.com.br/expresso/2016/10/16/O-que-\%C3\%A9-avaquejada.-E-por-que-ela-foi-proibida-pelo-Supremo>.

SARLET, I.W. A Eficácia dos Direitos Fundamentais: uma teoria geral dos direitos fundamentais na perspetiva constitucional. 11. ed. rev. e atual. Porto Alegre: Livraria do Advogado, 2012.

SIQUEIRA FILHO, V.; LEITE, R.A.; LIMA, V.B. A prática da vaquejada em xeque: considerações sobre a Ação Direta de Inconstitucionalidade n. 4.983. Revista Brasileira de Direito Animal, v.10, n.20, 2015.

WESCHENFELDER, P.N. Constituição e Cultura Ambiental. Curitiba: Juruá Editora, 2019. 